\title{
SER MÃE APÓS OS 35 ANOS: VANTAGENS E DESVANTAGENS DA MATERNIDADE SOB A ÓTICA DAS GESTANTES
}

\author{
BEING A MOTHER AFTER 35 YEARS OF AGE: ADVANTAGES AND \\ DISADVANTAGES OF MATERNITY FROM THE PERSPECTIVE OF \\ PREGNANT WOMEN
}

\begin{abstract}
Aline de Carvalho Martins ${ }^{1 *}$, Geiza Martins Barros ${ }^{2,3}$, Camila Rebouças Fernandes ${ }^{4}$, Géssica Martins Mororó ${ }^{5}$

${ }^{1}$ Instituto Nacional da Mulher da Criança do Adolescente, Rio de Janeiro, Rio de Janeiro, Brasil. ${ }^{2}$ Secretaria Municipal do Rio de Janeiro (SMS/HMMC) Rio de Janeiro, Rio de Janeiro, Brasil. ${ }^{3}$ Maternidade Escola (UFRJ), Rio de Janeiro, Rio de Janeiro, Brasil. ${ }^{4}$ Programa de Pós-Graduação de Políticas Públicas em Direitos Humanos da Universidade Federal do Rio de Janeiro, Rio de Janeiro, Rio de Janeiro, Brasil. ${ }^{5}$ Residência Multiprofissional em Saúde da Criança e do Adolescente Cronicamente Adoecidos no Instituto Nacional de Saúde da Mulher, da Criança e do Adolescente Fernandes Figueira (IFF/Fiocruz).

*Autor correspondente: Instituto Nacional da Mulher da Criança do Adolescente: Av Rui Barbosa, 716, Flamengo - Ambulatório de pré-natal. CEP 20021-1740. Email: rjalinemartins@yahoo.com.br
\end{abstract}

\section{RESUMO}

Introdução: Mudanças no perfil reprodutivo comportam novas demandas de atuação em saúde. Assim, é fundamental conhecer as tendências demográficas e refletir sobre as alterações que estas irão apresentar para os serviços de saúde. Objetivo: Conhecer as questões que perpassam o imaginário das gestantes em Idade Materna Avançada. Materiais e Métodos: O campo de pesquisa foi o Instituto Nacional de Saúde da Mulher, da Criança e do Adolescente Fernandes Figueira (IFF/Fiocruz). A técnica de coleta dos dados foi uma entrevista semiestruturada, com posterior análise temática proposta por Bardin. Foram abordadas 33 gestantes, das quais duas se recusaram a participar, perfazendo um total de 31 entrevistadas. Resultados e Conclusões: Emergiram duas categorias de análise: vantagens da maternidade após os 35 anos e desvantagens de ser mãe após os 35 anos. Na primeira categoria cabem destaques para a questão da maior maturidade, ter realizado seus projetos pessoais antes da gestação e segurança financeira. Já no que tange às dificuldades em ser mãe após os 35 anos, são destacadas questões referentes à tensão ou ansiedade quanto à possibilidade de malformação fetal, a possibilidade da falta de disposição física para acompanhar o ritmo e as demandas da criança, adversidades de saúde por envelhecimento materno, interrupção de projetos pessoais maternos, e sobrecarga materna devido à ausência paterna. Neste quesito também verificou-se a emergência da sub-categoria "nenhuma desvantagem". Diante deste contexto, os serviços de saúde possuem papel primordial no cuidado individualizado e na educação em saúde.

Palavras-chave: Idade materna, Gravidez, Saúde materna, Saúde da criança.

\begin{abstract}
Introduction: Changes in the reproductive profile present new demands to health care. Thus, it is fundamental to know the demographic trends and to reflect on the changes that these will present for the health services. Objective: To know the questions that occupy the minds of pregnant women in Advanced Maternal Age. Materials and Methods: The field of research was the Instituto Nacional da Saúde da Mulher, da Criança e do Adolescente Fernandes Figueira (IFF / Fiocruz). The technique of data collection was a semi-structured interview, followed by a thematic analysis as proposed by Bardin.
\end{abstract}


Thirty-three pregnant women were addressed, of whom two refused to participate, to a total of 31 interviewees. Results and Conclusions: Two categories of analysis emerged: advantages of motherhood after 35 years of age and disadvantages of being a mother after 35 years of age. In the first category stand out the issues of greater maturity, having carried out personal projects before pregnancy, and financial security. Regarding the difficulties of being a mother after the age of 35, stand out issues related to tension or anxiety regarding the possibility of fetal malformation, the possibility of lack of physical disposition to keep up with the child's energy and demands, health adversities due to maternal age, interruption of the mother's personal projects, maternal overload due to paternal absence. The "no disadvantage" sub-category also emerged. In this setting, health services play a key role in individualized care and health education.

Key words: Maternal age, Pregnancy, Maternal health, Child health.

\section{INTRODUÇ̃̃O}

Mudanças no perfil reprodutivo comportam novas demandas de atuação em saúde. Assim, é fundamental conhecer as tendências demográficas e refletir sobre as alterações que estas irão apresentar para os serviços de saúde. Em contextos de transição, desafios maiores estão postos, visto que é preciso reconhecer as questões que se alteram e demandam novas práticas dos profissionais de saúde, de modo a melhorar o cuidado prestado.

A literatura aponta que as gestações de mulheres com idade acima de 35 anos - consideradas pelo Ministério da Saúde em Idade Materna Avançada ${ }^{1}$ podem se desdobrar em resultados adversos. Estas são consideradas como gravidezes de risco, por serem "aquela[s] na[s] qual[/is] a vida ou a saúde da mãe e/ou do feto e/ou recém-nascido têm maiores chances de serem atingidas que as da média da população considerada" $"$.

Estas mulheres merecem especial atenção, pois constituem o único grupo etário que vem registrando um aumento de natalidade no Brasil ${ }^{3}$. Como se pode ver na tabela abaixo, este grupo de mulheres veio experimentando um aumento sistemático na natalidade entre os anos de 2000 e 2015.

No período estudado (2000-2015), ocorreram incrementos de nascimento da ordem de $44 \%$ no grupo de mulheres com idade entre 34 e 39 anos e um aumento de $30 \%$ nos grupos de mulheres com idade entre 40 e 44 anos. As mulheres com idade entre 45 e 49 anos permaneceram estáveis, com cerca de quatro mil partos ao ano. Mas foi no grupo de mulheres acima de 50 anos que a natalidade encontrou suas maiores altas. Sabe-se que estatísticas baseadas em casuísticas pouco numerosas são mais suscetíveis a maiores aumentos percentuais. E, embora o número de nascimentos seja reduzido neste público, os percentuais de aumento de nascimento são expressivos: uma elevação de $321 \%$ nos nascimentos entre mulheres entre 50 e 54 anos, e um aumento da ordem de $245 \%$ nos grupos de mulheres entre 55 e 59 anos $^{3}$.

O montante total mostra que nos grupos com idade superior a 35 anos, os nascimentos passaram de 275.277 no ano 2000 para 388.283 no ano de 2015 , ou seja, um crescimento de mais de $41 \%$, enquanto a natalidade geral no Brasil apresentou queda ${ }^{3}$.

Tabela 1. Distribuição dos nascimentos segundo idade materna no período de 2000 a 2014 .

\begin{tabular}{l|l|l|l|l|l|l|l|l}
\hline $\begin{array}{l}\text { Ano do } \\
\text { nascimento }\end{array}$ & $\begin{array}{l}\mathbf{3 5} \text { a 39 } \\
\text { anos }\end{array}$ & $\begin{array}{l}\mathbf{4 0} \text { a 44 } \\
\text { anos }\end{array}$ & $\begin{array}{l}\mathbf{4 5} \text { a 49 } \\
\text { anos }\end{array}$ & $\begin{array}{l}\mathbf{5 0} \text { a 54 } \\
\text { anos }\end{array}$ & $\begin{array}{l}\mathbf{5 5} \text { a 59 } \\
\text { anos }\end{array}$ & $\begin{array}{l}\mathbf{6 0} \text { a 64 } \\
\text { anos }\end{array}$ & $\begin{array}{l}\mathbf{6 5} \text { a 69 } \\
\text { anos }\end{array}$ & Total \\
\hline TOTAL & $\mathbf{3 . 4 8 1 . 5 7 4}$ & $\mathbf{8 9 4 . 3 4 8}$ & $\mathbf{6 2 . 7 9 0}$ & $\mathbf{2 . 7 1 1}$ & $\mathbf{4 1 0}$ & $\mathbf{8 9}$ & $\mathbf{4 7}$ & $\mathbf{4 . 4 4 1 . 9 6 9}$ \\
\hline 2000 & 214.808 & 55.665 & 4.690 & 93 & 20 & 1 & - & 275.277 \\
\hline 2001 & 211.149 & 55.032 & 4.691 & 96 & 14 & - & - & 270.982 \\
\hline 2002 & 213.590 & 55.388 & 4.195 & 65 & 10 & - & - & 273.248 \\
\hline 2003 & 212.614 & 55.880 & 4.154 & 87 & 12 & 4 & - & 272.751 \\
\hline 2004 & 215.873 & 58.370 & 3.842 & 98 & 11 & 2 & - & 278.196 \\
\hline
\end{tabular}


conclusão

\begin{tabular}{|l|l|l|l|l|l|l|l|l}
\hline $\begin{array}{l}\text { Ano do } \\
\text { nascimento }\end{array}$ & $\begin{array}{l}\mathbf{3 5} \text { a 39 } \\
\text { anos }\end{array}$ & $\begin{array}{l}\mathbf{4 0} \text { a } \mathbf{4 4} \\
\text { anos }\end{array}$ & $\begin{array}{l}\mathbf{4 5} \text { a } 49 \\
\text { anos }\end{array}$ & $\begin{array}{l}\mathbf{5 0} \text { a 54 } \\
\text { anos }\end{array}$ & $\begin{array}{l}\mathbf{5 5} \text { a 59 } \\
\text { anos }\end{array}$ & $\begin{array}{l}\mathbf{6 0} \text { a } \mathbf{6 4} \\
\text { anos }\end{array}$ & $\begin{array}{l}\mathbf{6 5} \text { a } \mathbf{6 9} \\
\text { anos }\end{array}$ & Total \\
\hline 2005 & 216.962 & 58.169 & 4.002 & 53 & 3 & 1 & - & 279.190 \\
\hline 2006 & 218.400 & 58.277 & 4.201 & 223 & 36 & 4 & 9 & 281.150 \\
\hline 2007 & 218.280 & 58.451 & 3.922 & 210 & 32 & 8 & 11 & 280.914 \\
\hline 2008 & 227.059 & 59.557 & 4.200 & 204 & 23 & 5 & 10 & 291.058 \\
\hline 2009 & 228.110 & 59.564 & 4.114 & 212 & 31 & - & - & 292.031 \\
\hline 2010 & 235.051 & 59.940 & 4.093 & 245 & 39 & 2 & 2 & 299.372 \\
\hline 2011 & 250.906 & 62.086 & 4.173 & 279 & 40 & 16 & 8 & 317.508 \\
\hline 2013 & 259.334 & 63.897 & 4.142 & 270 & 29 & 19 & 4 & 327.695 \\
\hline 2014 & 268.537 & 65.196 & 4.137 & 258 & 50 & 12 & 2 & 338.192 \\
\hline 2015 & 290.901 & 68.876 & 4.234 & 318 & 60 & 15 & 1 & 364.405 \\
\hline
\end{tabular}

Fonte: MS/SVS/DASIS - Sistema de Informações sobre Nascidos Vivos - SINASC

Diante dos dados apresentados e da relevância do assunto em questão, temos como indagações: Quais questões atravessam o imaginário dessas mulheres? Quais expectativas elas possuem quanto a seu futuro?

Ao se realizar uma busca no site da Biblioteca Virtual em Saúde, em fevereiro de 2018, utilizando o descritor Idade Materna Avançada, foram encontrados 62 resultados entre artigos (52), teses (3), perguntas e respostas (3), monografias (2), recursos de internet (1), e documentos de projeto (1). Ao reduzirmos a pesquisa a artigos e teses, e excluirmos trabalhos repetidos, aqueles que não abordavam o tema de forma central, e estudos de outros países, encontramos 19 resultados.

Se buscarmos o acúmulo do conhecimento brasileiro sobre o tema, veremos que os estudos em geral são escritos por profissionais da área biomédica clássica, como médicos, enfermeiros, nutricionistas, dentre outros, o que explicita muitas das temáticas abordadas em estudos sobre esta questão, centradas nos aspectos biológicos da reprodução em Idade Materna Avançada.

Nestes estudos, em geral, encontra-se uma contextualização fundamentada em uma realidade multicausal de âmbito sócio-político-econômico-cultural, capaz de estimular a gestação em uma idade considerada tardia. Cabe destaque para a valorização dos processos longos de escolarização/formação para o mercado de trabalho, a participação feminina no trabalho profissional, a menor paridade, os casamentos tardios, e as novas uniões conjugais ${ }^{4,5,6,7,8}$.

Entretanto, para além desta contextualização geral, verifica-se que o foco das pesquisas sobre este grupo tende a estar em sintonia com a formação dos autores. Os resultados dos estudos apresentam dados e novidades centrados nos aspectos de agravos à saúde física, à gestação, ao parto e às repercussões de saúde da criança com poucas informações sobre as mudanças nos processos de sociabilidade, as vivências hierárquicas de gênero ou as políticas públicas ${ }^{4,5,6,7,8,9,10,11,12,13}$.

Assim, em relação aos riscos e agravos maternos, observa-se estudos focados, principalmente, nas complicações obstétricas (trabalho de parto pré-termo, hemorragia anteparto, trabalho de parto prolongado, gestação múltipla, maior número de partos operatórios, placenta prévia, apresentações anômalas, distócias, pós-datismo, oligodramnia e polidrâmnio, rotura prematura de membranas) nos agravos potencializadores da mortalidade materna (pré-eclâmpsia, hemorragia pós-parto, placenta prévia, embolia por líquido amniótico, embolia pulmonar) e nos fatores prévios à gestação capazes de acarretar morbidades específicas para este período da vida, como: hipertensão arterial, diabetes, miomas, ganho de peso, obesidade $5,7,8,10,11,12$.

A literatura ressalta que os agravos na gestação em Idade Materna Avançada não se restringem à mulher, pois também podem se estender ao feto e/ou recém-nascido a partir do desenvolvimento de múltiplos agravos — abortamento espontâneo, maior risco de malformação, índice de Apgar menor que 7 no $1^{\circ} \mathrm{e}$ $5^{\circ}$ minutos de vida, baixo peso, restrição do crescimento fetal, sofrimento fetal, anormalidades cromossômicas e abortamentos espontâneos, mecônio intraparto, 
macrossomia, prematuridade e pós-maturidade, internação em UTI e óbito neonatal ${ }^{4,5,7,10,11,12,13}$.

Trata-se, portanto, de um consenso entre a literatura de que as gestações de mulheres em Idade Materna Avançada podem ser consideradas de alto risco, graças tanto aos fatores que assolam a saúde do bebê quanto às questões adversas maternas, o que associa este evento a uma necessidade de acompanhamento específico, considerando-se os riscos potencialmente envolvidos ${ }^{4,5,6,7,8,9,10,11,12,13}$.

Contudo, é preciso compreender a Idade Materna Avançada como um evento que ultrapassa a fisiologia feminina, pois trata-se de um fenômeno intimamente relacionado a um contexto social, econômico, político e ideológico. Desta forma, pode-se dizer que este acontecimento também é influenciado significativamente pelos modos de sociabilidade.

A gestação em Idade Materna Avançada é perpassada, diretamente, pelas relações sociais. As motivações para o adiamento da gestação são diversas e podem se vincular às ambições profissionais que exigem investimento, postergação da época do casamento, estabelecimento de novas uniões afetivas, dificuldades para a fertilidade e o acesso a uma diversificada disponibilidade de métodos contraceptivos ${ }^{10}$.

Considerando o atual padrão societário, que ainda valoriza a mulher como cuidadora e - mesmo que inserida no âmbito público — como a principal responsável pelos cuidados com as crianças, o adiamento da gestação vem se constituindo como uma estratégia para alcançar maiores níveis de qualidade de vida. $\mathrm{O}$ inverso também é verdadeiro.

Mulheres com mais anos de estudo e, portanto, níveis educacionais mais elevados, tendem a ter sua primeira relação sexual de forma protegida e, ao fazer uso de métodos contraceptivos ao longo da sua vida sexual, constituem famílias com menor número de membros ${ }^{10}$. Outros fatores também contribuem para a gestação na Idade Materna Avançada, incluindo o controle da natalidade, os avanços na tecnologia de reprodução assistida e na atenção à saúde de forma geral $^{11}$.

Alguns indicadores sociais diretamente relacionados às condições sociais destas mulheres, como a perspectiva de raça/cor ou de escolaridade, que se mostram diretamente atrelados ao lugar social das mulheres e que influenciam em suas escolhas reprodutivas, foram tratados em poucos estudos e somente de maneira transversal ${ }^{11,14}$.

Seus anseios, suas dúvidas e sua rede de apoio são elementos ainda pouco explorados pela literatura. Um exemplo disso é a ausência de questões acerca da contextualização familiar. Embora a literatura científica apresente reflexões sobre eventos de natureza social que irão influenciar no adiamento da maternidade, não se identifica análises sobre como os fatores apontados para o adiamento da reprodução impactam na vida das mulheres durante a gestação ou após a mesma.

Os fatores decorrentes das mudanças no mundo do trabalho e na sociedade em geral que repercutem na inserção da mulher no âmbito público, ampliam sua ocupação no mercado de trabalho, e alongam seu tempo de formação profissional, provavelmente irão se manter, o que requererá que os profissionais de saúde estejam preparados para oferecer assistência qualificada a este segmento ${ }^{8}$.

Deste modo, é possível pensar no quão desafiador este fenômeno pode ser para os profissionais de saúde, uma vez que são poucos os estudos consistentes sobre o perfil socioeconômico destas mulheres, sobre suas expectativas, questões e inseguranças. Considerando a complexidade do tema, é preciso ampliar a disseminação destas questões nos diferentes espaços, com o objetivo de torná-lo conhecido para os profissionais que atuam junto a este grupo.

A elaboração e a implementação de estratégias que visem a redução de resultados perinatais adversos, capacitando os profissionais envolvidos para "identificar precocemente sinais e sintomas de complicações e, ao mesmo tempo, contar com serviço de retaguarda que garanta a assistência e os exames que se fizerem necessários" "10, evitando as complicações gravídicas e resultados perinatais adversos que estão mais presentes em países em desenvolvimento, devido à escassez de cuidados adequados para este segmento ${ }^{8}$, mostram-se importantes para um cuidado específico, mas insuficientes para um atendimento com base na integralidade.

É preciso descobrir se as condições de melhoria na vida das mulheres - como o aumento da escolaridade — vêm se traduzindo em melhores possibilidades do exercício da maternidade e do desenvolvimento feminino. Há também que se refletir a respeito de quanto o contexto social adverso - como a falta de respaldo das políticas públicas para o cuidado com as crianças 
- se expressa no cotidiano destas mulheres que, em tese, possuem melhores condições de vida.

A única forma de compreender adequadamente este fenômeno é a partir da ótica dos sujeitos que o vivenciam. Descobrir seus projetos futuros, seus receios, sua rede de apoio e ideais, permitirá o delineamento de propostas de atuação em sintonia com suas realidades e demandas. A gestação constitui o início de uma mudança significativa em uma família, e a expectativa da chegada de uma criança implica em alterações da vida cotidiana e preparação para as transformações que irão ocorrer no futuro.

Já existem estudos mostrando o impacto da maternidade em determinados períodos da vida, como por exemplo, a adolescência ${ }^{15,16,17,18,19,20,21}$. Entretanto, não são encontrados estudos sobre as vantagens - e principalmente sobre as desvantagens — da maternidade após os 35 anos, sob a ótica dos sujeitos. Seriam estas as mesmas questões já conhecidas pelos serviços de saúde, ou estaríamos frente a questões específicas de um grupo em crescimento?

\section{MATERIAL E MÉTODO}

Considerando as reflexões pontuadas, apresentamos agora os resultados da pesquisa intitulada "Questões e expectativas que atravessam o cotidiano de mulheres em Idade Materna Avançada no Instituto Nacional de Saúde da Mulher, da Criança e do Adolescente Fernandes Figueira (IFF/Fiocruz)", na qual buscamos conhecer a realidade social e as questões que perpassam o imaginário das gestantes em Idade Materna Avançada sobre os impactos que a maternidade terá em diferentes aspectos de sua vida.

O campo de pesquisa foi o Instituto Nacional de Saúde da Mulher, da Criança e do Adolescente Fernandes Figueira (IFF/Fiocruz), que se caracteriza por ser uma unidade de referência do Ministério Saúde para o atendimento de gestação de alto risco fetal, atendendo a mulheres vindas de diversos pontos da cidade do Rio de Janeiro, de outros municípios e estados.

A cidade do Rio de Janeiro foi escolhida por ser uma grande metrópole, que apresenta questões parecidas com aquelas enfrentadas por outras capitais nacionais. Esperamos que os resultados desta pesquisa possam, de alguma forma, contribuir para a compreensão deste fenômeno em outras capitais.

$\mathrm{O}$ projeto foi desenvolvido consoante à Resolução $n^{\circ}$ 466/2012 do Conselho Nacional de
Saúde, que trata da pesquisa com seres humanos. Após a aprovação pelo Comitê de Ética em Pesquisa da instituição (CAAE: 51848015.0.0000.5269) realizamos pessoal e individualmente o convite para que as gestantes participassem do estudo. Neste momento, fornecemos esclarecimentos detalhados sobre os objetivos e a amplitude da pesquisa e sobre o sigilo ético-profissional que a envolve.

Após o contato inicial e a concordância dos sujeitos em participar da entrevista, coletamos dados empíricos através de entrevista semiestruturada, aplicada pelas pesquisadoras, com base em um roteiro pré-definido em sala individual e fechada. Esta entrevista foi gravada por meio digital.

Foram abordadas 33 gestantes, das quais duas se recusaram a participar, perfazendo um total de 31 entrevistadas. Foram excluídas deste estudo, por questões éticas, as mulheres cujos fetos eram considerados inviáveis, por considerar os possíveis prejuízos que esta entrevista poderia gerar.

A opção metodológica para definir o número final de entrevistadas se baseou na técnica da saturação de informações ${ }^{22}$, de modo que as entrevistas foram encerradas quando a coleta de dados parou de produzir novas informações ou quando as mesmas surgiam de modo recorrente em diversas entrevistas.

As questões norteadoras utilizadas para este artigo foram: Para você, como é estar grávida nesta idade? Quais as vantagens de estar grávida com esta idade? Quais as desvantagens de estar grávida com esta idade?

Após a realização das entrevistas, o material foi transcrito, a fim de constituir parte do corpus da pesquisa $^{22}$. Neste momento, também houve preocupação com a garantia de fidedignidade dos dados, de modo que todo o material transcrito foi submetido a uma revisão por parte da pesquisadora principal, a fim de garantir que as informações registradas correspondiam efetivamente às entrevistas realizadas.

Esta transcrição fidedigna das entrevistas foi submetida a uma análise temática ${ }^{23}$, o que possibilitou identificar informações e valores expressos por trás dos conteúdos tratados. O corpus da pesquisa foi submetido a três fases: pré-análise, exploração do material e tratamento/análise dos dados obtidos ${ }^{23}$.

\section{RESULTADOS E DISCUSSÃO}

Das 31 mulheres grávidas que participaram deste estudo, a maioria não planejou a gravidez. As 
entrevistadas tinham idade mínima de 35 de anos (critério de inclusão) e máxima de 43 anos, sendo a faixa etária de 35 a 39 anos a mais prevalente. A cor da pele autorreferida foi majoritariamente parda. Mais da metade das mulheres possuía uma atividade remunerada e encontrava-se em união ou com companheiro na ocasião da entrevista.

Após exploração minuciosa do material obtido e sua posterior análise, emergiram duas categorias de análise: vantagens da maternidade após os 35 anos e desvantagens de ser mãe após os 35 anos.

$\mathrm{Na}$ primeira categoria cabem destaques para a questão da maior maturidade, possibilidade de aproveitar melhor a fase da gestação, autoavaliação mais positiva de sua própria capacidade de cuidar da criança, ter realizado seus projetos pessoais antes da gestação e segurança financeira.

Já no que tange às dificuldades de ser mãe após os 35 anos, são destacadas as questões referentes à tensão ou ansiedade quanto à possibilidade de malformação fetal, a possibilidade da falta de disposição física para acompanhar o ritmo do crescimento e as demandas da criança, adversidades de saúde por envelhecimento materno, interrupção de projetos pessoais maternos, sobrecarga materna devido à frágil ou nula participação paterna. Neste quesito também verificou-se a emergência da subcategoria "nenhuma desvantagem".

\section{Vantagens da maternidade após os 35 anos}

A bibliografia indica que as mulheres com mais idade têm maior vantagem e maturidade emocional para o exercício da maternidade $24,25,26,27$. No caso da pesquisa do presente artigo não é diferente: um dos elementos mais expressivos mencionados pelas entrevistadas quanto às vantagens de estar grávida com 35 anos ou mais, foi a maturidade:

Acho que eu estou mais madura, tenho uma expectativa muito grande e espero que a gente acerte agora, porque diz que a idade avançada tem certas dificuldades... Mas eu tô bem confiante e a expectativa é grande (E1).

Eu acho que você está mais madura. (...) então a minha vantagem de ser mãe agora é que eu tenho uma cabeça mais madura (E6).

A vantagem é que a gente tá mais madura, mais preparada, mais estruturada, você sabe... Porque, né... Eu e meu marido já estamos juntos há 19 anos. E a maturidade (E23).
A última fala apresenta a maturidade como uma vantagem de estar grávida após os 35 anos, associada à estabilidade de uma união afetiva e a necessidade de ter um filho, considerando o tempo de relacionamento do casal. Quanto a este elemento, a literatura afirma que mulheres em Idade Materna Avançada estão, em maior proporção, vivendo com os pais de seus filhos ${ }^{25}$ e possuem uma rede de apoio considerada importante ${ }^{26}$.

As mulheres em Idade Materna Avançada tendem a fazer um comparativo de suas experiências maternas anteriores e atuais ${ }^{26}$. Neste sentido, ao mesmo tempo em que a gestação tardia para essas mulheres vem acompanhada de maturidade e responsabilidade, elas ressaltaram a possibilidade de melhor aproveitamento da fase da gravidez, principalmente quando comparada com gravidezes anteriores:

Eu acho que mãe com 39 anos quanto mais velha, mais boba (E2).

$\mathrm{Eu}$ acho que eu estou curtindo bem mais a gravidez, porque a minha primeira gravidez eu tinha 16 anos, então era bem jovem. As outras duas foram bem pontuadas, então não deu para curtir muito, e agora dessa gravidez eu tenho curtido mais (E15).

Ah, sei lá... Vantagem de... A gente se sente mais mãe, né?! Mesmo ainda estando na barriga (E30).

No relato que apresentaremos a seguir, a entrevistada associa o fato de aproveitar mais a gravidez com a maturidade e com a vivência de uma relação afetiva considerada estável. A entrevistada se refere a estes fatores como "tudo direitinho":

Olha eu tô, na verdade eu tô curtindo mais, tô me sentindo mais madura, mais plena, mais bem resolvida, mais segura, estando em um casamento, entendeu?! Tudo direitinho. Então hoje estou me sentido melhor, dessa vez nessa gestação foi totalmente diferente, eu estou me sentido mais plena, entendeu?! Mais feliz (E14).

Esta fala indica, ainda, que a situação conjugal da mulher faz com que ela tenha uma experiência diferenciada de gravidez, mais positiva. Além disso, este relato aponta para uma normatização de casamento e maternidade que, segundo a entrevistada, é a forma "correta" desta experiência. A entrevistada faz um comparativo entre o modo como vivenciou isso antes e a forma como está vivenciando atualmente, ressaltando a experiência atual como ideal.

Ainda abordando as vantagens de ser mãe com 35 anos ou mais, as entrevistadas fizeram uma avaliação positiva do desempenho materno, destacando que se sentem mais seguras nos cuidados com a criança: 
Porque você já tem mais experiência, que talvez se eu tivesse filho na época que eu queria mesmo, que era lá pelos 20, talvez eu não tivesse essa bagagem que você vai pegando com um e com outro... Além do mais que eu trabalho em escola, eu falo que eu sei ligar dos 6 anos até os 17, agora após esse período, vai ser uma experiência nova. Então fica mais fácil... Você já absorve as coisas melhor, é bem mais fácil (E4).

As vantagens que eu vejo é o conhecimento, eu com 24 ainda era muito imatura em relação de ser mãe, né?! Eu acho que hoje, depois que eu consegui aceitar essa gravidez, que foi bem rápido, por conta que eu passei pela psicóloga, eu me ajudei, teve pessoas que me ajudaram... E assim eu percebo que é tudo mais fácil, da aceitação de como eu vou desenvolver com a criança, e esse lado, com 24 eu tinha insegurança, a vantagem dos 35 é essa, eu estou mais preparada para isso. No começo eu até senti medo, porque eu já tenho um com 12 pré-adolescente, né... E ter um bebê, mas hoje isso já tá bem esclarecido na minha cabeça, coisa que aos 24 não estava. Eu tinha receio em ser mãe, medo de não dar conta... Até na hora da amamentação, esse tipo de coisas que eu não tenho isso, eu acho que vou lidar bem com essas situações, como eu tô conseguindo na gestação (E12).

A gente não tá mais crua, a gente já sabe, tipo assim... Cuidar se tá com uma cólica, cuidar de um... Já sabe diferenciar se de repente já é uma cólica de coisa, se é uma manha da criança... Se a criança tá sentindo alguma coisa, se não tá. Porque quando a gente é muito nova, a criança chora e você não sabe porquê que tá chorando... Você não sabe porquê... Se tá chorando de repente porque tá com dor na barriga, se tá com dor no ouvido. Tudo isso a gente se desespera, hoje em dia a gente fica mais controlada, né?! Tá mais madura... Tá criando filho assim, nessa idade, acho que a gente fica mais... Mais esperta, né?! (E27).

Hoje em dia, é... Eu vou ter muito mais cuidado, eu sei o que, que... Eu já sabia, quando eu tava com as minhas filhas, mas hoje em dia, eu tô sabendo de coisas, coisas que eu não sabia, que eu tinha 28 anos quando eu tive minhas filhas. Hoje, com 39 anos... (E31).

Estes achados se entrelaçam com a maturidade na gestação tardia, trabalhada pela literatura ${ }^{24,25,26,27} \mathrm{e}$ tão referenciada pelas mulheres. Nota-se que as mulheres fazem um comparativo com suas gestações anteriores e com experiências para além da própria maternidade. Ou seja, até mesmo as mulheres mais velhas que não são mães acabam por se considerar, neste caso, experientes, pelo fato de terem acesso ao assunto da maternidade seja academicamente, profissionalmente ou em conversas informais.
Neste âmbito, outro elemento que se destacou na fala das entrevistadas, foi o fato de terem conseguido realizar seus projetos pessoais antes da gravidez:

Acho maravilhoso. Porque estou mais velha, eu acho que é diferente de ter uma gravidez como a gente vê essas meninas super jovens. Eu acho que na parte profissional, o que tinha para realizar eu realizei, o que tinha para fazer eu fiz (E7).

Ótimo. Porque como eu nunca quis ter antes, até mesmo para estudar. (...) Então eu comecei a faculdade com 23 anos, eu nunca tinha feito nada, nem namorava, nada disso (E2).

A vantagem é que eu fiz tudo o que podia fazer, viajei à vontade, namorei, trabalhei, estudei, fiz e aconteci sem preocupação com filho! Consegui fazer a faculdade, terminar. (...) E foi bom porque eu consegui fazer não tudo o que eu gostaria, mas fiz bastante coisa, essa é a vantagem (E9).

Além dos elementos apresentados anteriormente, a produção científica aponta que mulheres que engravidam com 35 anos ou mais apresentam condições econômicas mais favoráveis e tendem a ter maior planejamento econômico quanto ao nascimento do primeiro filho ${ }^{27}$, o que as coloca em uma posição financeiramente vantajosa para se tornarem mães ${ }^{26,28}$.

Acho que a principal é o amadurecimento, financeiramente estou um pouco mais estabilizada e todo dia a gente acorda para matar um leão, para trabalhar, para crescer... E eu acho que a maternidade está ficando cada vez mais tardia por causa disso, mas eu acho que a condição que eu vou ter até de educar e até de ela ter coisas que eu não tive. Eu tive que correr muito atrás trabalhando desde muito nova, ela vai conseguir ter melhor do que eu tive... Então, pra mim é isso (E7).

Porque você tem uma experiência da vida, é mais vivida... Sei lá, você busca uma coisa melhor, um trabalho melhor. Na época que fui mãe, tinha 15 anos... Eu não tinha casa, não tinha trabalho e hoje você tem a cabeça melhor para poder dar uma estrutura melhor para a criança (E16).

Eu acho vantagem porque eu sou mais madura, tenho meu trabalho, sou independente e dos outros [filhos] não [estava trabalhando]... Tava estudando, tinha que depender do pai, da mãe, do marido (E24).

Neste contexto, pode-se dizer que as mulheres associam a idade avançada à maior segurança financeira, o que pode estar relacionado a mais anos de estudo e qualificação profissional, inserção mais solidificada no mercado de trabalho ${ }^{24,27,29,30}$ A Idade Materna Avançada acontece, muitas vezes, em um cenário em que seus projetos já estão consolidados, fazendo com que as mulheres pausem projetos já estabelecidos, para os 
quais elas poderão retornar menos dificilmente algum tempo depois.

\section{Desvantagens de ser mãe após os 35 anos}

Nesta categoria serão apresentadas as percepções que, de alguma forma, se mostraram inconvenientes para as mulheres. Destacou-se, nas falas, uma tensão ou ansiedade por parte das mulheres em ter um bebê com a possibilidade de malformação, associada à Idade Materna Avançada:

(...) então eu já fico mais apreensiva e é o que eu falei... Às vezes a gente acaba lendo: passou dos 35, já tem dificuldade. E de repente também do bebê vir com alguma deformidade de alguma coisa... (E1).

(...) com medo de nascer com problema, sei lá... Porque dizem que tem risco depois dos 35 anos, o óvulo da mulher fica mais velho. Eu peço a Deus que venha com saúde, porque ter filho já dá trabalho e vindo complicado fica mais trabalhoso ainda, né... (...) Só a preocupação mesmo de nascer com alguma coisa assim, mas fora isso, não (E16).

Já não é a mesma coisa a gente ter filho assim com 20, 24 ... A gente sabe que já tem um certo risco de a criança nascer com Síndrome de Down, essas coisas... (E22).

Eles tão achando tudo, eles só falam do neném... Eles só falam de comprar as coisas pro neném, aí eu fico com medo da decepção, alguma coisa (E25).

Essa tensão está associada, também, como na última fala, ao que as outras pessoas - principalmente os familiares ${ }^{24}$ - irão pensar sobre uma gestação tardia e as condições de saúde e de estética da criança. Além disso, as mulheres associaram a idade a maiores chances de ter um bebê com condições crônicas de saúde, algo que já está consagrado pela literatura como um fator de risco ${ }^{24,29,30,31,32}$.

No entanto, é preciso ter cuidado ao abordar essas questões com a mulher grávida, uma vez que "rotular" a gestação como sendo de risco já é capaz de introjetar na gestante expectativas negativas para uma gravidez que pode ser considerada tranquila ${ }^{32}$.

Outro elemento que se sobressaiu nos relatos das entrevistadas foi a idade, enquanto um fator que dificulta o acompanhamento do ritmo de crescimento e das demandas da criança:

Bom, eu acho que é o cansaço... Pessoas mais velhas se sentem mais cansadas e aí eu tenho medo que, devido ao cansaço, eu deixe correr solto. (...) então, assim, que não posso deixar correr solto, porque mais tarde quem sofre é ela... (E2).

Eu tenho medo de ter uma filha adolescente e eu estar muito velha e não conseguir acompanhar... Eu fico pensando nisso toda hora: já pensou, minha filha com 15 anos e eu vou estar com 51, como será que minha cabeça vai estar? Será que eu vou acompanhar? Eu fico com medo de morrer e quem vai cuidar dela... E umas coisas mais ou menos assim que eu acho que se eu fosse mais nova, não teria essas preocupações (E7).

A desvantagem é que eu vou ser mãe-vó porque quando ela tiver 15, eu já tenho 55 (E9).

Mas assim, a única desvantagem que eu vejo é a questão do teu pique... Não é mais a mesma coisa. Se eu faço algum esforço, quando é no final do dia, a coluna está arrebentada...Quando era mais nova não tinha isso, nem ligava, não sentia nada (E14).

Estas não parecem ser questões específicas deste estudo. Outros estudos afirmaram que a idade é um elemento de destaque para as mulheres em Idade Materna Avançada, quando estas foram questionadas sobre a capacidade física e fatores emocionais na gravidez ${ }^{24}$. Além disso, apontam que a gestação tardia, em seus aspectos clínicos, acaba por estigmatizar as mulheres como "grávidas idosas"32.

Associada à questão da disposição física para acompanhar os filhos, as mulheres também citaram as condições adversas de saúde que podem afetar elas mesmas, atreladas ao envelhecimento materno. A literatura indica que a Idade Materna Avançada pode contribuir para o surgimento de doenças crônicas com mais frequência, além de apresentar fatores adversos especificamente à gestação ${ }^{25,29,30,31,32,33,34}$, se configurando como uma preocupação para os serviços de saú$\mathrm{de}^{33}$. Nos fragmentos abaixo, fica explícito que a Idade Materna Avançada não é uma preocupação somente dos serviços:

Depois dos 30 tudo aparece... Dor na coluna e eu, pouco antes de engravidar, eu descobri que eu poderia estar com esporão. O peso dói um pouco a perna, eu tenho sentido bastante dores nas pernas e as desvantagens é que você não está tão durinha assim, os ossos já começam a reclamar... E tem a hipertensão, a diabete, que eu tenho caso na família, então a minha desvantagem é essa... (E4).

A questão da saúde, porque você não tem tanta saúde... Mexe com a pressão, glicose e você também não tem tanta paciência, tempo, né... (E11).

Eu me sinto mais cansada! (...) eu vi essa desvantagem da idade... Tive as mesmas complicações, né. Desenvolvi hipertensão durante as duas gravidezes, fiz ciclagem nas duas gravidezes e me sentia mais ativa, eu não me sentia uma grávida de alto risco. Conseguia fazer movimentos, conseguia ter uma predisposição física maior... E agora eu sinto mais o cansaço físico (E21). 
Nota-se que ao mesmo tempo em que as mulheres se sentem mais capacitadas e experientes para exercer a maternidade, elas apresentam as condições físicas como desvantajosas. Quanto a essas questões, a literatura é explícita ao afirmar que o corpo passa por um processo de envelhecimento, perdendo capacidades consideradas fundamentais para um desenvolvimento gestacional considerado adequado ${ }^{26,32}$.

Mesmo na gravidez em idade avançada, foi possível destacar alguns relatos das mulheres em que elas explicitam que a maternidade significa, neste momento, a interrupção de alguns projetos pessoais:

E você perder a liberdade, vai deixar de fazer algumas coisas e gravidez não prende homem, gravidez prende mulher... Desde o começo, gravidez prende mulher! (...) Ah, eu acho que eu vou estudar menos... Talvez eu tenha que abrir mão de um sonho, porque eu não tenho como largar mão de uma criança com os outros, aí talvez eu tenha que abrir mão de uma faculdade, de um curso, de uma viagem... (E8).

Perda da liberdade, do meu espaço. A gente tinha planos de viajar... (E10).

De fato, este achado condiz com o que tem sido trabalhado por alguns autores que, ao realizarem um estudo com mulheres em Idade Materna Avançada, reafirmaram que o nível de escolaridade dessas mulheres é expressivamente maior, refletindo maiores investimentos na vida acadêmica e profissional ${ }^{25}$. Neste âmbito, a gravidez, para essas mulheres, demonstra ser a interrupção de determinados projetos relacionados a outras esferas da vida para além da maternidade, como, por exemplo, a interrupção dos estudos, a redução de carga horária do trabalho fora de casa, ou o afastamento do mercado de trabalho para se dedicarem integralmente aos cuidados com a criança e com a casa.

A bibliografia atenta para a carreira como prioridade na vida da mulher atualmente, o que se caracteriza pelo adiamento da maternidade com o objetivo de atingir a consolidação profissional ${ }^{26,29,36}$. Neste contexto, é válido pontuar que mesmo as mulheres que já possuem uma carreira consolidada tendem a abrir mão de alguns projetos quando engravidam.

Outro fator que chama a atenção, mas que não é uma novidade na literatura científica, é a sobrecarga materna devido ao vácuo deixado pela ausência da figura masculina enquanto alguém que poderia influenciar na vivência da gestação:

(...) e questão de você não ter um marido presente conta muito, né?! Porque quando é uma gestação que você tem um marido do teu lado, assim no dia a dia, é diferente... (E11).

Existem estudos que destacam a ansiedade e a insatisfação das mulheres quando estas são consideradas as únicas capazes de cuidar da criança. Esta é uma perspectiva negativa para as mulheres, pois reforça estereótipos de gênero e contribui para que as mulheres sejam as principais cuidadoras das crianças, interrompendo alguns projetos para exercer a maternidade ${ }^{36}$.

Chama atenção a presença de algumas entrevistadas que se negaram a identificar qualquer desvantagem na gravidez. Estas mulheres, quando indagadas, afirmaram que não existia nenhuma desvantagem em ser mãe com 35 anos ou mais:

\section{Não (E13).}

Nenhuma (risos)... Eu não acho nenhuma desvantagem, porque meu filho é uma benção, e nessa gravidez, eu tô saudável (E17).

Não tem nenhuma, eu acho... É começar tudo de novo... (E20).

Embora estes relatos não tenham sido predominantes, é preciso analisá-los com bastante cuidado para entender que mesmo sabendo de todas as condições adversas de saúde para a mãe e o bebê, essas mulheres não classificam o fenômeno como desvantagem.

Não foram encontrados, na literatura científica, maiores estudos que justifiquem esses relatos, o que se configura como uma novidade. Porém, cabe refletir que essas mulheres podem não ter se sentido à vontade para afirmar que há desvantagens em ser mãe nessa faixa etária ou, simplesmente, a maternidade para elas é algo tão positivo, que acaba por anular as expectativas negativas com relação à idade avançada.

\section{CONCLUSÃO}

Mulheres com "Idade Materna Avançada" são um fenômeno crescente no Brasil. Este fenômeno pode ser atribuído, também, à percepção feminina de sua exclusiva responsabilidade pelos cuidados infantis. Neste contexto, postergar a gestação para materializar seus projetos de vida se destaca como uma estratégia capaz de conjugar estabilidade financeira, consolidação de uma carreira e maternidade tardia.

Os fatores considerados como vantajosos para estas mulheres (estar mais madura, mais estabilizada financeiramente e mais confiante com a sua capacidade de cuidar) permitirão que os serviços de saúde se deparem com gestantes empolgadas em vivenciar este 
momento e com disponibilidade para frequentar o serviço e receber orientação. Neste contexto, as práticas profissionais tendem a ser mais facilitadas.

Por outro lado, os fatores considerados negativos por estas mulheres (possibilidade de malformação fetal, maior cansaço físico para o cuidado do filho, sobrecarga feminina gerada pela ausência do pai da criança), também constituem fatores estressores a serem abordados como parte integrante do atendimento pré-natal prestado a estas mulheres.

Entender as peculiaridades de uma gestação nesta fase da vida implica reconhecer que, mesmo já podendo ter experimentado a maternidade em um outro momento, estas mulheres não devem ser tratadas como gestantes já capacitadas e sem demandas para os cuidados com elas e com seus bebês. Pelo contrário; estas mulheres, em virtude da maturidade oriunda da idade, se interessam em ser atualizadas em novas tecnologias de cuidado, para uma melhor qualidade de vida da criança.

Também apresentou-se como necessária a disponibilização de espaços de diálogo coletivos, para que também possam ser expressas as adversidades vivenciadas neste momento da vida, de forma que as mulheres não sejam pressionadas a negar as vivências desconfortáveis deste período. Acolher as mulheres em sua integralidade significa oportunizar espaços de diálogo franco e verdadeiro, inclusive em relação às possibilidades de futuro associadas à malformação fetal e às consequências desta realidade para o futuro desta mulher.

Por último, cabe aos serviços de saúde o desenvolvimento de ações que estimulem o cuidado infantil compartilhado entre homens e mulheres. Percebe-se que nos casos em que existe uma coabitação entre o casal, este seria um trabalho propício para evitar a sobrecarga materna e garantir maiores possibilidades de vínculo, interação e cuidado para a criança.

\section{REFERÊNCIAS}

Brasil MS. Secretaria de Atenção à Saúde. Departamento de Ações Programáticas Estratégicas. Gestação de alto risco: Manual técnico. $5^{\text {a }}$ ed. Brasília: Editora do Ministério da Saúde; 2010.

Caldeyro-barcia, R. et al. Frecuencia cardíaca y equilibrio acido base del feto. Montevideo: Centro Latinoamericanode Perinatologia y Desarrollo Humano, 1973. (Publicación científica del CLAP, n. 519).
Brasil MS. Datasus. Informações em saúde. Estatísticas vitais. Nascidos vivos (SINASC), 2003-2013. [citado em 28 de agosto de 2018]. Disponível em: http://tabnet.datasus. gov.br/cgi/deftohtm.exe?sinasc/cnv/nvuf.def.

Almeida NKO, Almeida RMVR, Pedreira CE. Adverse perinatal outcomes for advanced maternal age: a crosssectional study of Brazilian births. J. Pediatr. (Rio J.) [Online]. 2015 Oct [cited 2018 Mar 24]; 91 (5): 493 - 498. Available from: http://www.scielo.br/scielo.php?script=sci arttext\&pid=S0021-75572015000500493\&lng=en

Bezerra ACL, Mesquita JSB, Maria CC, Santos RBd, Teixeira FV. Desafios Enfrentados por Mulheres Primigestas em Idade Avançada. Revista Brasileira de ciências da saúde. [Online]. 2015 [citado em 05 de setembro de 2018]; 19 (2): 163-168. Disponível em: http://periodicos.ufpb.br/ojs/ index.php/rbcs/article/view/24335.

Canhaçço EE, Bergamo AM, Lippi UGL, Reginaldo, GC. Perinatal outcomes in women over 40 years of age compared to those of other gestations. Einstein (São Paulo) [Online]. 2015 [cited 2018 Sep 5]; 13(1): 58-64. Available from: http://www.scielo.br/scielo.php?script=sci arttext\&pid=S1679-45082015000100011\&lng $=$ en\&nrm $=\overline{\mathrm{i}}$ so.

Ribeiro, FD et al. Extremes of maternal age and child mortality: analysis between 2000 and 2009. Rev. Paul. Pediatr. (São Paulo) [Online]. 2014 Dec [cited 2018 Aug 28]; 32(4): 381-388. Available from: http://www. scielo.br/scielo.php?script $=$ sci_arttext\&pid=S010305822014000400381\&lng=en\&nrm=iso.

Gonçalves ZR, Monteiro DLM. Complicações maternas em gestantes com Idade Materna Avançada. Revista Femina [Online]. Set 2012 [citado em 28 de agosto de 2018]; 40(5): 275-279. Disponível em: http://files.bvs.br/ upload/S/0100-7254/2012/v40n5/a3418.pdf

Figuerêdo ED, Lamy FF, Lamy ZC, Silva AAM. Maternal age and adverse perinatal outcomes in a birth cohort (BRISA) from a Northeastern Brazilian city. Rev. Bras. Ginecol. Obstet. [Online]. 2014 Dec [cited 2018 Aug 28]; 36( 12): 562-568. Available from: http:// www.scielo.br/scielo.php?script=sci_arttext\&pid=S010072032014001200562\&lng=en. Epub Nov 21, 2014. http:// dx.doi.org/10.1590/SO100-720320140005161.

Gravena AAF, Sass A, Marcon SS, Pelloso SM. Resultados perinatais em gestações tardias. Rev. esc. enferm. USP (São Paulo) [Online]. Fev 2012 [citado em 5 de setembro de 2018]; 46 (1):15-21. Disponível em: http://www. scielo.br/scielo.php?script=sci_arttext\&pid=S0080 62342012000100002\&lng=en.

Santos GHN, Martins MG, Sousa MS, Batalha SJC. Impacto da idade materna sobre os resultados perinatais e via de parto. Rev. Bras. Ginecol. Obstet. [Online]. Jul. 2009 [citado em 28 de Agosto de 2018]; 31(7): 326-334. 
Disponível em: http://www.scielo.br/scielo.php?script=sci arttext\&pid $=$ S0100-72032009000700002\&lng=en.

Cunha KS, Bertuzzo CS. Perfil da Idade Materna na síndrome de Down: levantamento de 35 anos. [Tese de Conclusão de curso de aprimoramento]. Campinas (SP): Programa de genética molecular e citogenética, Universidade Estadual de Campinas; 2008. Disponível em http://ses.sp.bvs.br/lildbi/ docsonline/get.php?id=5699.

Gusmão FAF, Tavares EJM, Moreira LMA. Idade materna e síndrome de Down no Nordeste do Brasil. Cad. Saúde Pública [Online]. Ago 2003 [citado em 28 de agosto de 2018]; 19(4):973-978. Disponível em: http://www. scielo.br/scielo.php?script=sci_arttext\&pid=S0102311X2003000400020\&lng=en.

Santos NB, Novo NF, Gonçalves RP, Bassaneze ST. Perfil das mulheres acometidas por prenhez ectópica tubária. Revista Femina. [Online]. Ago 2007 [citado em 28 de agosto de 2018];35(8):477-481.

Martins, AC. Paternidade: significados e dilemas presentes entre homens em um hospital pediátrico no Rio de Janeiro. $1^{\mathrm{a}}$ ed. Rio de Janeiro: Novas Edições Acadêmicas, 2014.

Martins, AC. Maternidade adolescente e (des)proteção pública: contribuições para a crítica ao risco social. $1^{\text {a }}$ ed. Rio de Janeiro: Novas Edições Acadêmicas, 2014.

Sabroza AR, Leal MC, Souza JPR. Gama Silvana Granado Nogueira da. Algumas repercussões emocionais negativas da gravidez precoce em adolescentes do Município do Rio de Janeiro (1999-2001). Cad. Saúde Pública (Rio de Janeiro) [Online]. 2004 [citado em 5 de setembro de 2018]; 20(Sup. 1): S130-S137. Disponível em: http:// www.scielo.br/scielo.php?script=sci_arttext\&pid=S0102$311 X 2004000700014 \& \operatorname{lng}=$ en.

Oliveira RC. Adolescência, gravidez e maternidade: a percepção de si e a relação com o trabalho. Saúde soc. (São Paulo) [Online]. Dez 2008 [citado em 28 de agosto de 2018]; 17(4): 93-102. Disponível em: http://www. scielo.br/scielo.php?script=sci_arttext\&pid=S010412902008000400010\&lng=en.

Hoga LAK. Maternidade na adolescência em uma comunidade de baixa renda: experiências reveladas pela história oral. Rev. Latino-Am. Enfermagem [Online]. Mar 2008 [citado em 5 de setembro de 2018]; 16(2): 280-286. Disponível em: http://www.scielo.br/pdf/rlae/v16n2/pt_17. pdf

Dias AB, Aquino EML. Maternidade e paternidade na adolescência: algumas constatações em três cidades do Brasil. Cad. Saúde Pública (Rio de Janeiro) [Online]. Jul 2006 [citado em 5 de setembro de 2018]; 22(7): 1447-1458. Disponível em: http://www.scielo.br/pdf/csp/v22n7/09.pdf

Andrade PR, Ribeiro CA, Silva CV. Mãe adolescente vivenciando o cuidado do filho: um modelo teórico.
Rev. bras. enferm. [Online]. Fev 2006 [citado em 28 de Agosto de 2018]; 59(1):30-35. Disponível em: http:// www.scielo.br/scielo.php?script=sci_arttext\&pid=S0034$71672006000100006 \& \operatorname{lng}=$ en.

Bauer M, Aarts B. A construção do corpus: um princípio para a coleta de dados qualitativos. In: BAUER, M.; GASKELL, G. (orgs) Pesquisa qualitativa com texto, imagem e som: um manual prático. Petrópolis: Vozes, 2002.

Bardin L. Análise de Conteúdo. Lisboa: Edições 70, 1979.

Coelho DDR, Jéssica LAS, Maria MSMT, Jefferson D. Gravidez e maternidade tardia: sentimentos e vivências de mulheres em uma unidade de pré-natal de alto risco em Barreiras, Bahia. Revista Hígia (Bahia) [Online]. 2017 [citado em 28 de agosto de 2018]; 2(1): 1-19. Disponível em: http://fasb.edu.br/revista/index.php/higia/article/view/145.

Bárbara M, Francisca P, Edgar M, Sandra V, Margarida A , Joana S. Ser Mãe Depois dos 35 Anos: Será Diferente? Revista Científica da Ordem dos Médicos [Online]. Set 2017 [citado em 28 de agosto de 2018]; 30(9):615-622.

Lopes MN, Dellazzana-Zanon LL, Boeckel MG. A Multiplicidade de Papéis da Mulher Contemporânea e a Maternidade Tardia. Trends in Psychology/Temas em Psicologia [Online]. 2014 [citado em 28 de agosto de 2018]; 22(4): 917-928. Disponível em: http://pepsic. bvsalud.org/scielo.php?script=sci_arttext\&pid=S1413389X2014000400018.

Oliveira RB, Galdino DP, Cunha CV, Paulino EFR. Gravidez após os 35: uma visão de mulheres que viveram essa experiência. Corpus et Scientia [Online]. Nov 2011 [citado em 5 de setembro de 2018]; 7(2): 99-112. Disponível em: http://apl.unisuam.edu.br/revistas/index. $\mathrm{php} /$ corpusetscientia/article/view/134.

Lima LC. Idade materna e mortalidade infantil: efeitos nulos, biológicos ou socioeconômicos? Rev. Bras. Estud. Popul. (Rio de Janeiro) [Online]. Jun.2010 [citado em 5 de setembro de 2018]; 27(1): 211-226. Disponível em: http:// www.scielo.br/scielo.php?script=sci_arttext\&pid=S0102$30982010000100012 \& \operatorname{lng}=\mathrm{en} \& \mathrm{nrm}=\overline{\mathrm{iso}}$.

29. Viera Neta FA, Crisóstomo VL, Castro RCMB, Pessoa SMF, Aragão MMS, Calou CGP. Avaliação do perfil e dos cuidados no pré-natal de mulheres com diabetes mellitus gestacional. Rev Rene [Online]. Out 2014 [citado em 28 de Agosto de 2018]; 15(5): 823-831. Disponível em: http://repositorio.ufc.br/bitstream/riufc/10657/1/2014_art_ cgpcalou.pdf.

Falcão PJ, Torres RPP, Gasparetto A, Farinha LB, Mattos KM. Parto e idade: características maternas do estado do rio grande do sul. Saúde (Santa Maria) [Online]. Nov 2013 [citado em 28 de agosto de 2018]; 39(2): 99-108. Disponível em: https://periodicos.ufsm.br/revistasaude/ article/view/6304. 
Pimenta AM, Nazareth JV, Souza KV, Pimenta GM. Programa "Casa das Gestantes": perfil das usuárias e resultados da assistência à saúde materna e perinatal. Texto contexto Enferm (Florianópolis) [Online]. Out 2012 [citado em 28 de agosto de 2018]; 21(4):912-920. Disponível em: http://www.scielo.br/pdf/tce/v21n4/23.pdf.

Gomes AG, Donelli TMS, Piccinini CA, Lopes RCS. Maternidade em idade avançada: aspectos teóricos e empíricos. Interação em Psicologia. [Online]. Jun 2008 [citado em 28 de agosto de 2018]; 12(1): 99-101. Disponível em: http://revistas.ufpr.br/psicologia/article/ view/5242/9214

Caetano LC, Netto L, Manduca JNL. Gravidez depois dos 35 anos: Uma revisão sistemática da literatura. Rev. Min. Enferm. [Online]. Out 2011 [citado em 5 de setembro de 2018]; 15(4): 579-587. Disponível em: http://www.reme. org.br/artigo/detalhes/73.

Amadei JL, Merino CG. Hipertensão arterial e fatores de risco em gestantes atendidas em unidade básica de saúde. Revista saúde e pesquisa. [Online] Jan 2010 [citado em 28 de agosto de 2018]; 3(1): 33-39. Marques B, et al. Ser mãe depois dos 35 anos, Acta Med Port 2017 Sep;30(9):615622. Disponível em: file:///C:/Users/PC/Downloads/831929120-2-PB.pdf.

Marques B, et al. Ser mãe depois dos 35 anos, Acta Med Port 2017 Sep;30(9):615-622. Disponível em: file://C:/ Users/PC/Downloads/8319-29120-2-PB.pdf

Beltrame GR, Donelli TMS. Maternidade e carreira: desafios frente à conciliação de papéis. Aletheia. [Online]. Mai 2012 [citado em 5 de setembro de 2018]; (38-39): 206-217. Disponível em: http://pepsic.bvsalud.org/scielo. php? script=sci_abstract\&pid=S1413-03942012000200017. 